\title{
Faulty antenna detection in a linear array using simulated annealing optimization
}

\author{
Navaamsini Boopalan ${ }^{1}$, Agileswari K.Ramasamy ${ }^{2}$, Farrukh Hafiz Nagi ${ }^{3}$ \\ ${ }^{1,2}$ Department of Electronics and Communications Engineering, University Tenaga Nasional, Malaysia \\ ${ }^{3}$ Department of Mechanical Engineering, University Tenaga Nasional, Malaysia
}

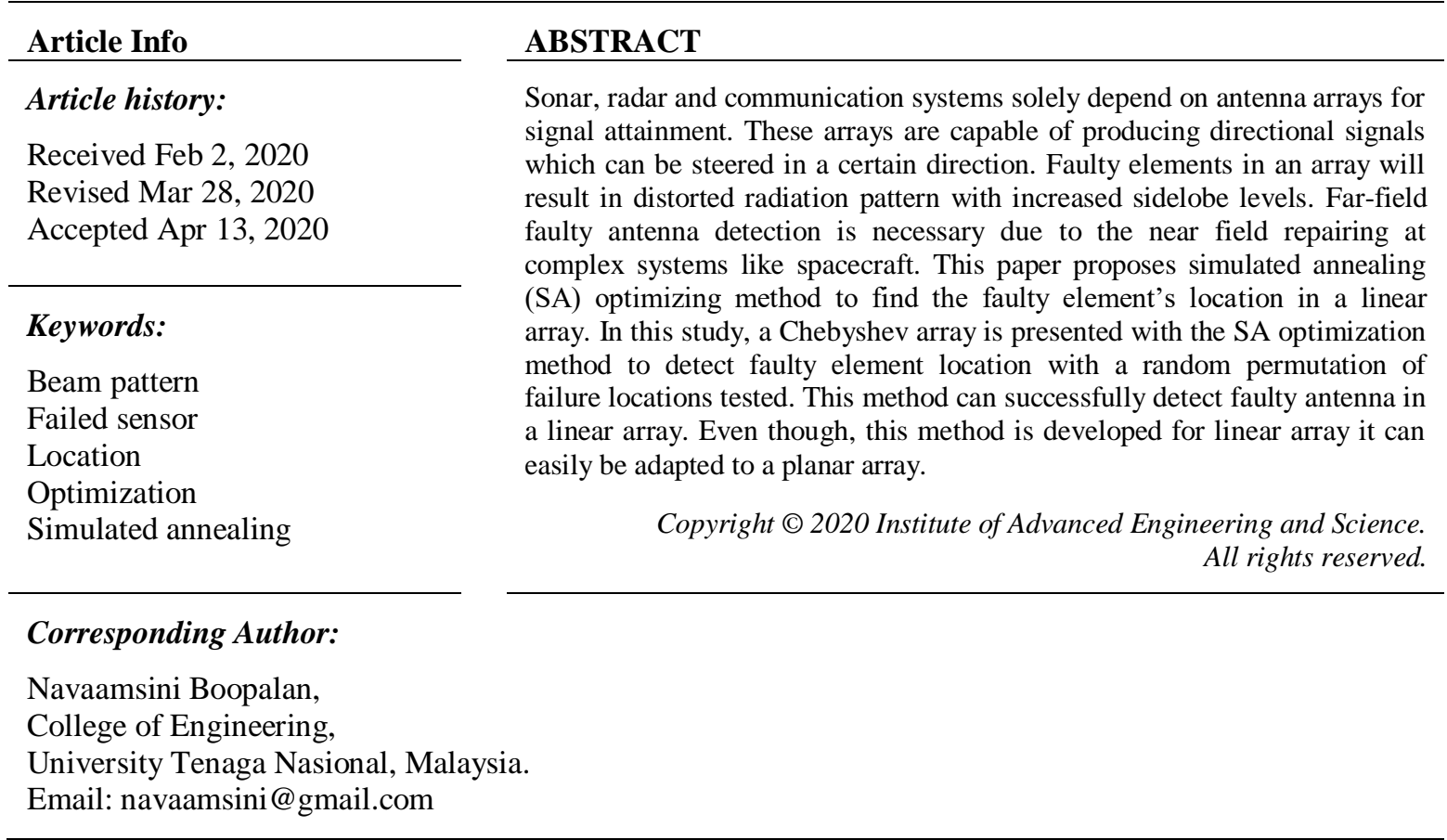

\section{INTRODUCTION}

Antenna arrays play a vital role in various fields like sonar, radar and communication systems for its signal attainment which can generate directed signals that can be steered to the desired angle. Normally, the arrays are designed with a large number of elements which will eventually increase the probability of faulty elements in an array. The faulty elements ruin the symmetry of the array and rigorously distort the radiation pattern with increased sidelobe levels. The usual way is to take near field measurements of the antenna to find the failed element in an array [1-3]. It is not practical to apply this convention method in remote systems like spacecraft where the system is inaccessible by humans [4]. However, another way to detect the failed elements is to use test couplers and calibration probes which are expensive and complex to use [5]. This increases the necessity of more research on a far-field radiation pattern to find the failed element(s) in an array [6]. On the other hand, literature [7-10] suggested correction or compensation for the failed radiation pattern. However, information on the number and the position of the failed element is required to apply the corrections to the array.

Authors in the previous works have used artificial neural network [11,12] to detect failed locations. This method maps the radiation pattern of a faulty array at different sets of combinations and trains the network. While in [13], the author has suggested a Multi-class Support Vector Classifier (SVC) for planar array failure diagnosis. These methods are limited to the on-off type of fault where antennas were considered as completely failed or completely working; no consideration was executed for partial failure or a certain percentage of failure of the elements in the array. Whereas, optimizations using the firefly algorithm [14], bacteria foraging technique [15] and fast Fourier transform [16] solves fault-finding with complete and partial failure in an array. Other than that, a Hybrid genetic algorithm with parallel coordinate descent [17] and a Hybrid cultural algorithm with differential evolution [18] is suggested by Khan S. U. et. al for a large 
number of elements in an array. The recent research is proving that an efficient algorithm to find the faulty element in an array is still continuing.

This paper presents a simulated annealing optimization method to detect the faulty element's location and the percentage of failure in an array. Simulated annealing method is suitable in finding the lowest value during the objective function optimization which is known as global minima in the presence of other lower value known as local minima. It is an adaptation of the Monte Carlo method to generate a sample state of the thermodynamic system [19]. This method is used in various fields like solving network coverage problems [20], power system distribution [21], component location optimization [22] and solving multi-objective problems like production scheduling [23]. Previous work with this method related to failed elements in an array is to optimize the performance of the array [24]. But, no research has been done with this method to locate the failed elements in an array. A failed Dolph-Chebyshev pattern is generated with some faulty antenna in an array. Simulated annealing optimization is developed for the failed pattern to find the failed element location in the array. The method is successful in finding the failed location. The rest of the article is organized as follows. Section 2 compromises methodology while in Section 3 the SA method is provided. Section 4 discusses the simulation and results and this paper is concluded with Section 5.

\section{METHODOLOGY}

In order to test the proposed method, a beam pattern with failed elements is generated. A classical Dolph-Chebyshev linear array with 32 elements, $\lambda 2$ inter-element spacing and -30db constant SLL is used as the original array beam pattern and, failed elements are then randomly generated on this beam pattern. Then, the SA algorithm is developed to find the location(s) of the failed element(s). The details to generate the classical radiation pattern failed radiation pattern and simulated annealing method for failed element detection is discussed in the upcoming sections.

\subsection{Beam pattern generation}

The array factor of a classical Dolph-Chebyshev linear array beampattern with $N$ elements, $(N=32)$ with equally spaced non uniform amplitude is given as (1) [25] below.

$$
G(\theta)=\sum_{n=1}^{N} w(n) e^{i(2 n-N-1) * a r g}
$$

where

$$
\arg =\pi d\left[\sin \left(\theta-\frac{\pi}{2}-\gamma\right)\right]
$$

$\theta$ is scanning angle,

$\gamma$ is the steering angle

$w(n)$ is Chebychev weights on each element

$d$ Inter-element distance between array elements

$N=32$, Array elements and $n$ is the index

Failed radiation pattern with one or more faulty element(s) is calculated by using (1) and assigning the values for failed weights, $w_{f}$ depending on the level percentage of failure. A zero weight for completely failed element, $50 \%$ of weight at a partially failed element or $75 \%$ of weight for three quarter failed element from the initial Chebyshev weights. Modified (1) for the failed radiation pattern is (3) [26] below.

$$
G_{f}\left(\theta_{k}\right)=\sum_{n=1}^{N} w_{f}(n) e^{i(2 n-N-1) * \arg }
$$

$G_{k}\left(\theta_{k}\right)$ will be treated as $k$-th radiation pattern (current) while $G_{f}\left(\theta_{k}\right)$ will be the far-field radiation pattern. The optimization will compare far-field pattern with the current radiation pattern and minimize the objective function. The objective function is defined as

$$
\text { error }=\sum_{n=1}^{N}\left(\left(G_{f}\left(\theta_{k}\right)-G_{k}\left(\theta_{k}\right)\right)^{2}\right.
$$

Minimization in the objective function in return will give the weights or known as excitation amplitude of each element in the array. 


\subsection{Simulated annealing algorithm}

Simulated annealing (SA) method falls under a stochastic optimization family which is similar to the Genetic Algorithm (GA) and Evolutionary Algorithm (EA). Normally, an initial design is changed using combinatorial analysis and evaluated with the objective function. SA allows the optimization to find an optimal solution to the design. The analogy of metal annealing is used in this which will reduce the objective function similar to temperature reduction in metal annealing process.

\subsubsection{Simulated annealing for failed element detection}

The desired calculation of SA is to detect the failed array element location in (3). The SA optimization searches are implemented by Monte-Carlo random searches. After every search, a new radiation pattern is formed and compared with reference far-field failed pattern. The error, in (4) represents the convergence of the successful detection of the failed array element. After running the optimization, the error value is checked. If error $\neq 0$, then the number of the sensor is increased by one and the procedure to find the failed location is repeated. If it is zero, the optimization ends by showing the weights at each element in the array including the failed elements. Figure 1 explains the SA optimization in flow chart representation.

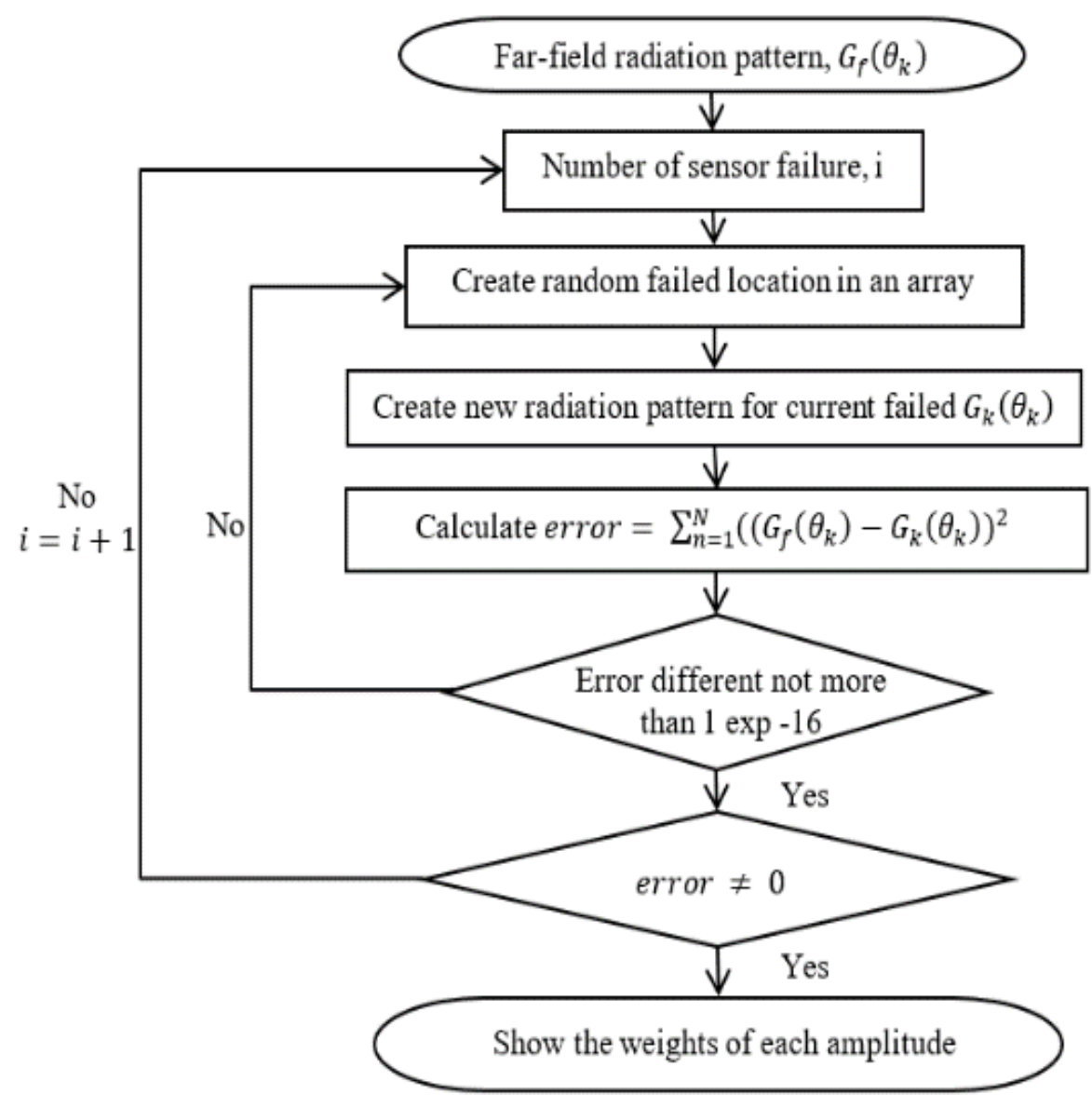

Figure 1. Flowchart representation of SA

\section{RESULTS AND ANALYSIS}

The classic Chebyshev array radiation for 32 elements is generated with (1). The array pattern and its normalized weight distribution is shown in Figure 2. Then, the elements in the array are failed to test if the algorithm is able to detect the element(s) that failed in the array. For this purpose, $14^{\text {th }}, 6^{\text {th }}$ and $23^{\text {rd }}$ element of an array is selected randomly. The optimization will start from one failure in the array and increases the number of element if the error after SA optimization is not equaled to zero as shown in Figure 1 earlier. The test was limited to three element failure as most of the literature has remained the number of failure to three in their works. Firstly, to test the ability to finding one or more element failure in an array, $14^{\text {th }}$ element 
is completely failed; then, $14^{\text {th }}$ and $6^{\text {th }}$ elements are failed; and lastly, $14^{\text {th }}, 6^{\text {th }}$ and $23^{\text {rd }}$ elements are failed. For all the conditions, the optimization method managed to find the failed element(s) accurately. The initial Chebyshev weights and weights after running SA for all elements in the array are summarized in Table 1. It is observed that the SA managed to find the weights of completely failed elements as zero for all the specified locations and for all three conditions. Figure 3(a) shows the original Chebyshev array pattern and failed pattern for the $14^{\text {th }}, 6^{\text {th }}$, and $23^{\text {rd }}$ elements completely failed. Figure 3(b) shows its weight distribution. It is observed that the failure at three completely failed locations can severely damage the radiation pattern.
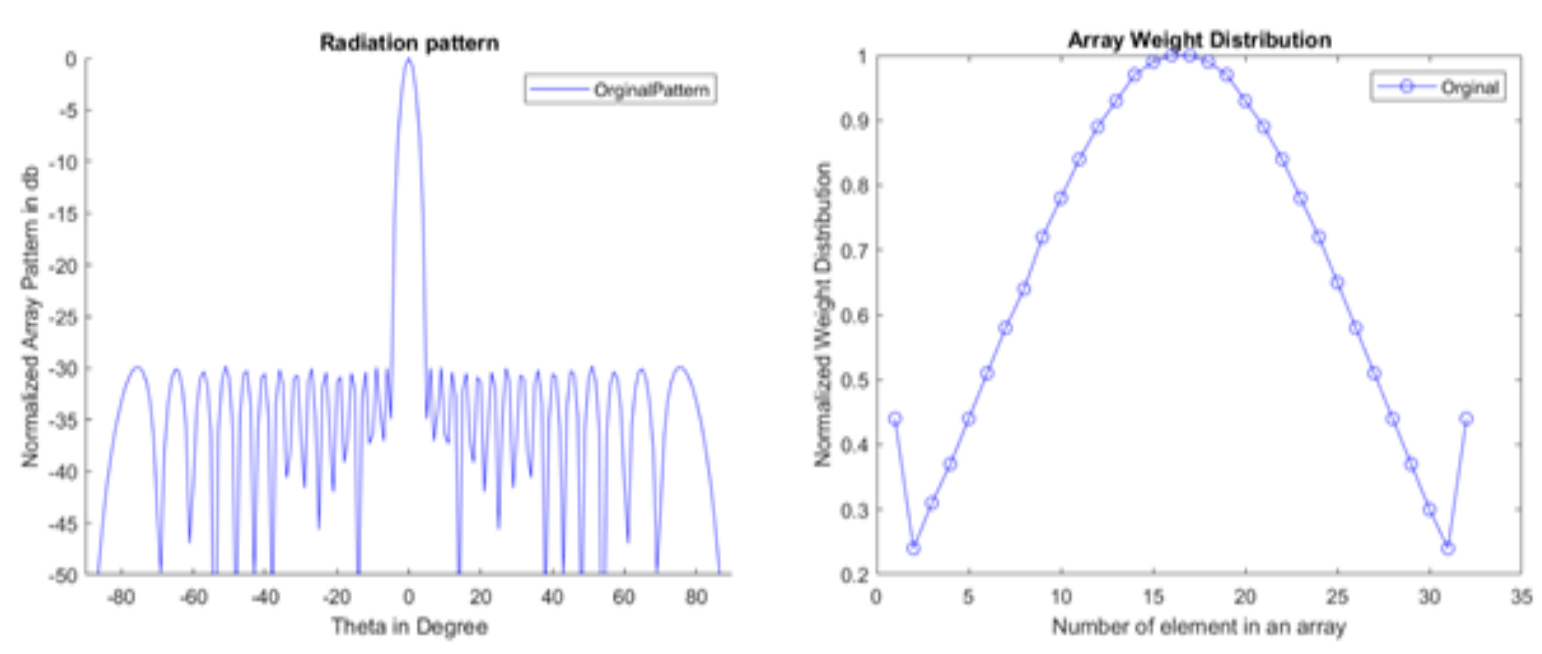

Figure 2. Original Chebyshev array pattern for 32 elements and its normalized weight distribution

Table 1. Original chebyshev weights and weights obtained by simulated annealing

\begin{tabular}{|c|c|c|c|c|}
\hline $\begin{array}{l}\text { Element } \\
\text { Number }\end{array}$ & $\begin{array}{c}\text { Chebyshev } \\
\text { Weights }\end{array}$ & $\begin{array}{l}14^{\text {th }} \text { element } \\
\text { Failed }\end{array}$ & $\begin{array}{l}14^{\text {th }} \text { element } \& 6^{\text {th }} \\
\text { element Failed }\end{array}$ & $\begin{array}{c}14^{\text {th }} \text { element, } 6^{\text {th }} \\
\text { element } \& 23^{\text {rd }} \text { Failed }\end{array}$ \\
\hline 1 & 0.44 & 0.44 & 0.44 & 0.44 \\
\hline 2 & 0.24 & 0.24 & 0.24 & 0.24 \\
\hline 3 & 0.31 & 0.31 & 0.31 & 0.31 \\
\hline 4 & 0.37 & 0.37 & 0.37 & 0.37 \\
\hline 5 & 0.44 & 0.44 & 0.44 & 0.44 \\
\hline 6 & 0.51 & 0.51 & 0 & 0 \\
\hline 7 & 0.58 & 0.58 & 0.58 & 0.58 \\
\hline 8 & 0.64 & 0.64 & 0.64 & 0.64 \\
\hline 9 & 0.72 & 0.72 & 0.72 & 0.72 \\
\hline 10 & 0.78 & 0.78 & 0.78 & 0.78 \\
\hline 11 & 0.84 & 0.84 & 0.84 & 0.84 \\
\hline 12 & 0.89 & 0.89 & 0.89 & 0.89 \\
\hline 13 & 0.93 & 0.93 & 0.93 & 0.93 \\
\hline 14 & 0.97 & 0 & 0 & 0 \\
\hline 15 & 0.99 & 0.99 & 0.99 & 0.99 \\
\hline 16 & 1 & 1 & 1 & 1 \\
\hline 17 & 1 & 1 & 1 & 1 \\
\hline 18 & 0.99 & 0.99 & 0.99 & 0.99 \\
\hline 19 & 0.97 & 0.97 & 0.97 & 0.97 \\
\hline 20 & 0.93 & 0.93 & 0.93 & 0.93 \\
\hline 21 & 0.89 & 0.89 & 0.89 & 0.89 \\
\hline 22 & 0.84 & 0.84 & 0.84 & 0.84 \\
\hline 23 & 0.78 & 0.78 & 0.78 & 0 \\
\hline 24 & 0.72 & 0.72 & 0.72 & 0.72 \\
\hline 25 & 0.65 & 0.65 & 0.65 & 0.65 \\
\hline 26 & 0.58 & 0.58 & 0.58 & 0.58 \\
\hline 27 & 0.51 & 0.51 & 0.51 & 0.51 \\
\hline 28 & 0.44 & 0.44 & 0.44 & 0.44 \\
\hline 29 & 0.37 & 0.37 & 0.37 & 0.37 \\
\hline 30 & 0.3 & 0.3 & 0.3 & 0.3 \\
\hline 31 & 0.24 & 0.24 & 0.24 & 0.24 \\
\hline 32 & 0.44 & 0.44 & 0.44 & 0.44 \\
\hline
\end{tabular}




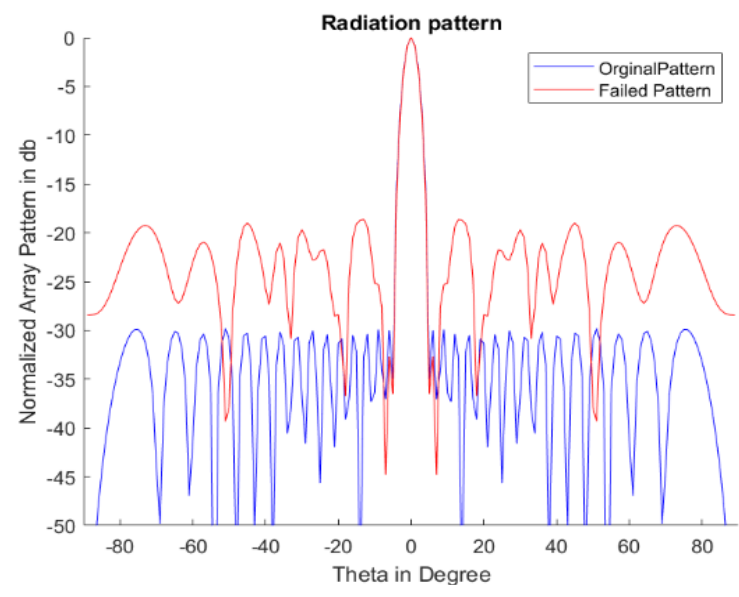

(a)

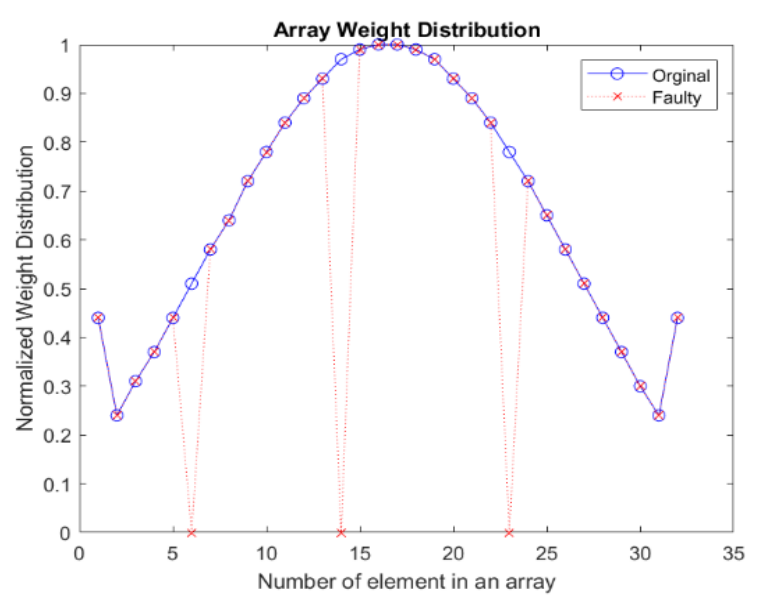

(b)

Figure 3. The original Chebyshev array pattern and failed pattern for $14^{\text {th }}, 6^{\text {th }}$, and $23^{\text {rd }}$ elements completely failed and its normalized weight distribution

Figure 4 shows the distribution of the weights of the array elements after running SA optimization. The SA optimization managed to find the failed element's location similar to far-field defected radiation pattern. Other than that, failure percentage with complete failure element (100\%), partial failure element $(50 \%)$, and three-quarter failure element $(75 \%)$ were also tested. For the next condition, $14^{\text {th }}$ element three-quarter failed $(75 \%), 6^{\text {th }}$ element partial failed $(50 \%)$ and the $23^{\text {rd }}$ element completely failed $(100 \%)$ far-field radiation pattern is simulated. Figure 5(a) shows the original radiation pattern and failed radiation pattern. Figure 5(b) shows its weight distribution throughout the array elements. Complete faulty element with zero weight, a partial faulty element with $50 \%$ of initial weight and three-quarter element failure with $25 \%$ from its initial weight can be clearly observed from the figure. Then, SA was run to locate the failed elements.

Figure 6 shows the weights of the original pattern and weights obtained after running SA. It is observed that the SA can successfully find the failed element's location and the percentage failure precisely after the optimization. The algorithm can be modified to increase the number of failures in an array if needed.

Then, other random failure permutations were also tested with different locations and different percentages of failures to test the accuracy of the SA method. All results obtained by SA were recorded in Table 2. The results of the failed location found are bold in the table. The results prove that SA is capable of detecting the percentage failure in each element at random locations accurately.

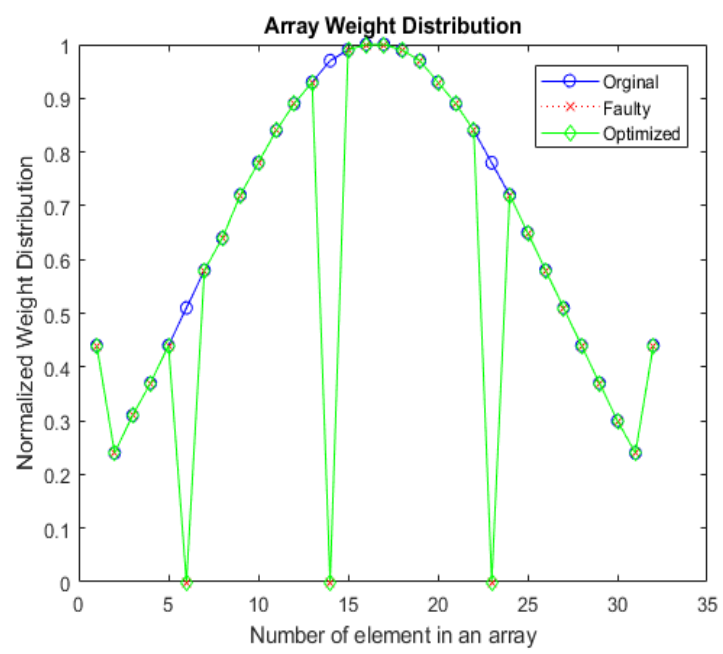

Figure 4. The distribution of the weights of the $14^{\text {th }}, 6^{\text {th }}$, and $23^{\text {rd }}$ elements completely failed array elements after running SA optimization 


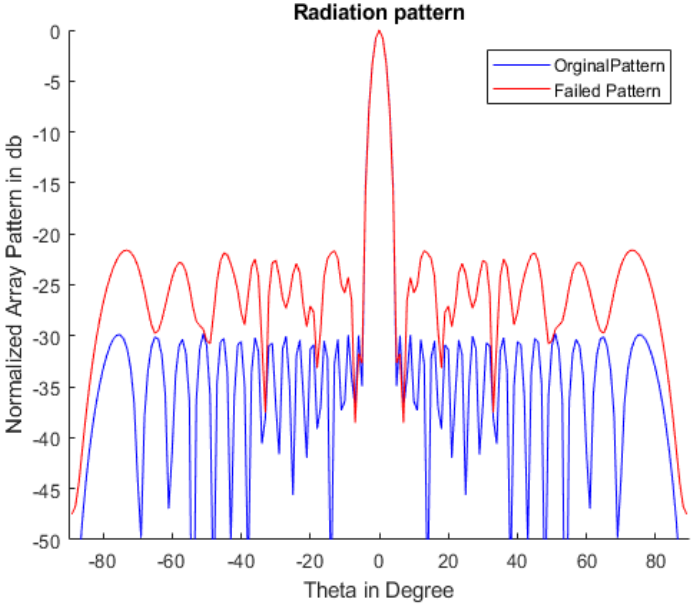

(a)

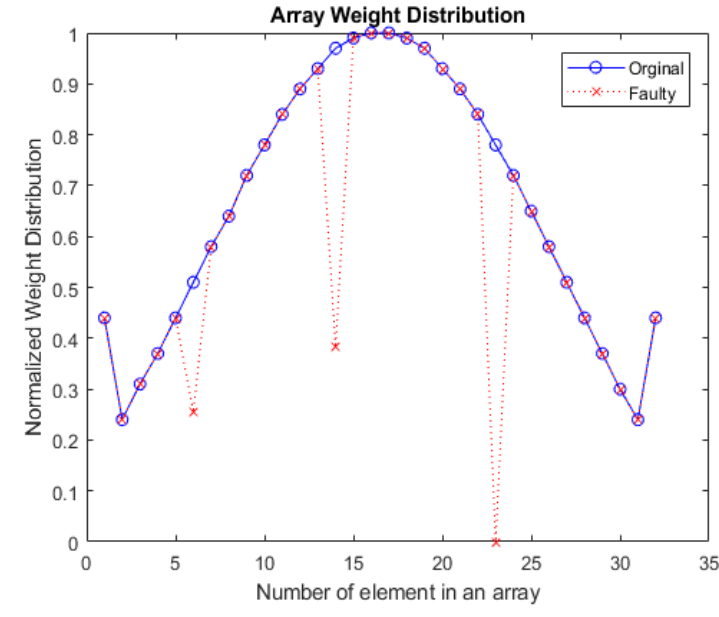

(b)

Figure 5(a). Original Chebyshev array pattern and failed pattern for $14^{\text {th }}$ element failed $75 \%, 6^{\text {th }}$ element failed $50 \%$ and the $23^{\text {rd }}$ element completely failed (100\%) Figure 5(b). Weight distribution of Original Chebyshev array pattern and Failed pattern for $14^{\text {th }}$ element failed $75 \%, 6^{\text {th }}$ element failed $50 \%$ and $23^{\text {rd }}$ element completely failed $(100 \%)$

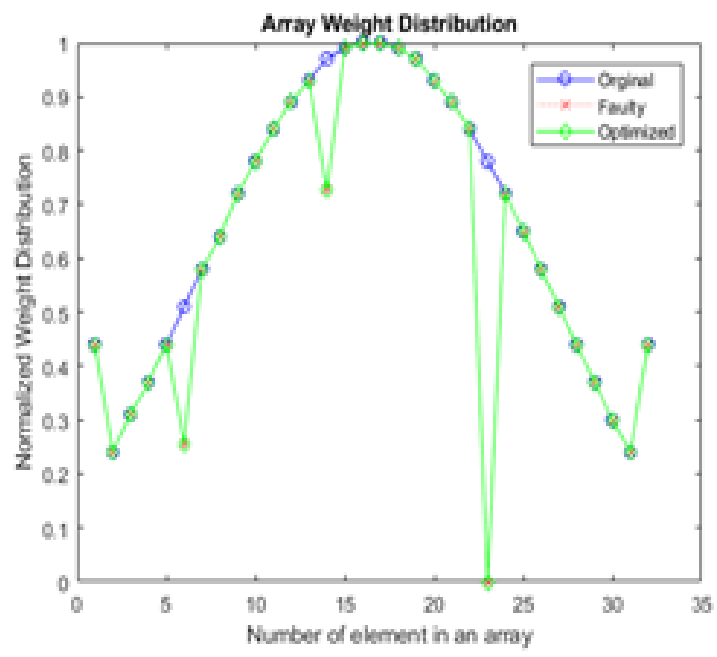

Figure 6. Original Chebyshev normalized weight distribution, Faulty elements and SA optimized weights for $14^{\text {th }}$ element failed $75 \%, 6^{\text {th }}$ element failed $50 \%$ and $23^{\text {rd }}$ element completely failed $(100 \%)$

Table 2. Original chebyshev weights and weights obtained by simulated annealing for different

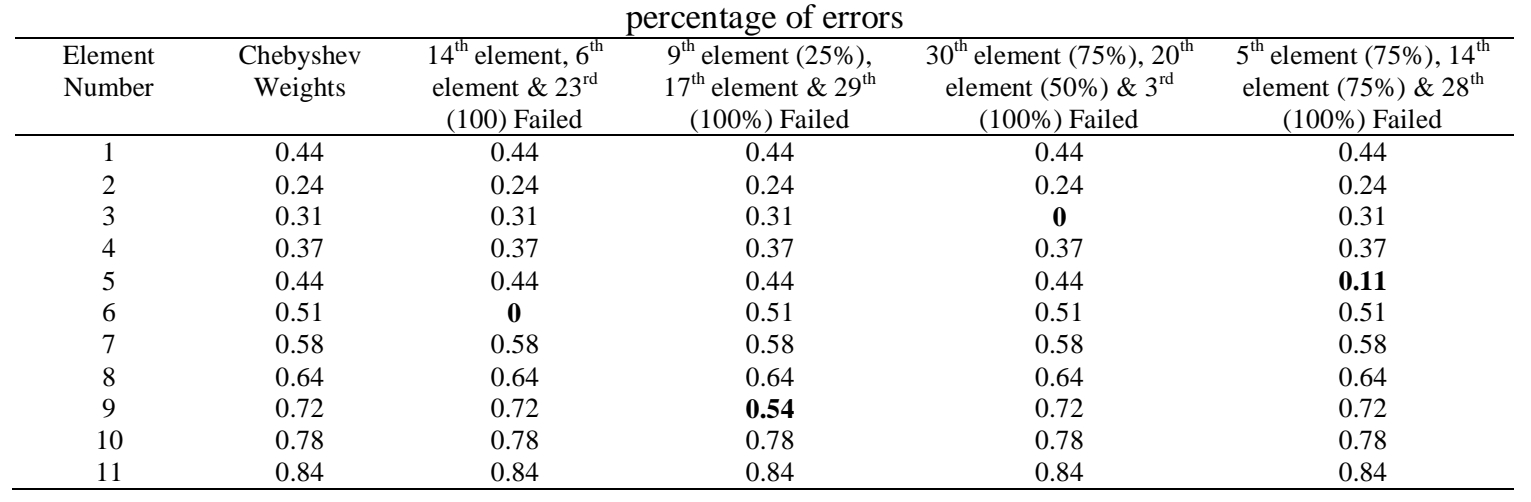

Faulty antenna detection in a linear array using simulated annealing optimization ... (Navaamsini Boopalan) 


\begin{tabular}{|c|c|c|c|c|c|}
\hline $\begin{array}{l}\text { Element } \\
\text { Number }\end{array}$ & $\begin{array}{c}\text { Chebyshev } \\
\text { Weights }\end{array}$ & $\begin{array}{l}14^{\text {th }} \text { element, } 6^{\text {th }} \\
\text { element } \& 23^{\text {rd }} \\
(100) \text { Failed }\end{array}$ & $\begin{array}{l}9^{\text {th }} \text { element }(25 \%), \\
17^{\text {th }} \text { element } \& 29^{\text {th }} \\
(100 \%) \text { Failed }\end{array}$ & $\begin{array}{c}30^{\text {th }} \text { element }(75 \%), 20^{\text {th }} \\
\text { element }(50 \%) \& 3^{\text {rd }} \\
(100 \%) \text { Failed }\end{array}$ & $\begin{array}{l}5^{\text {th }} \text { element }(75 \%), 14^{\text {th }} \\
\text { element }(75 \%) \& 28^{\text {th }} \\
(100 \%) \text { Failed }\end{array}$ \\
\hline 12 & 0.89 & 0.89 & 0.89 & 0.89 & 0.89 \\
\hline 13 & 0.93 & 0.93 & 0.93 & 0.93 & 0.93 \\
\hline 14 & 0.97 & $\mathbf{0}$ & 0.97 & 0.97 & 0.2425 \\
\hline 15 & 0.99 & 0.99 & 0.99 & 0.99 & 0.99 \\
\hline 16 & 1 & 1 & 1 & 1 & 1 \\
\hline 17 & 1 & 1 & $\mathbf{0}$ & 1 & 1 \\
\hline 18 & 0.99 & 0.99 & 0.99 & 0.99 & 0.99 \\
\hline 19 & 0.97 & 0.97 & 0.97 & 0.97 & 0.97 \\
\hline 20 & 0.93 & 0.93 & 0.93 & 0.465 & 0.93 \\
\hline 21 & 0.89 & 0.89 & 0.89 & 0.89 & 0.89 \\
\hline 22 & 0.84 & 0.84 & 0.84 & 0.84 & 0.84 \\
\hline 23 & 0.78 & $\mathbf{0}$ & 0.78 & 0.78 & 0.78 \\
\hline 24 & 0.72 & 0.72 & 0.72 & 0.72 & 0.72 \\
\hline 25 & 0.65 & 0.65 & 0.65 & 0.65 & 0.65 \\
\hline 26 & 0.58 & 0.58 & 0.58 & 0.58 & 0.58 \\
\hline 27 & 0.51 & 0.51 & 0.51 & 0.51 & 0.51 \\
\hline 28 & 0.44 & 0.44 & 0.44 & 0.44 & $\mathbf{0}$ \\
\hline 29 & 0.37 & 0.37 & $\mathbf{0}$ & 0.37 & 0.37 \\
\hline 30 & 0.3 & 0.3 & 0.3 & 0.075 & 0.3 \\
\hline 31 & 0.24 & 0.24 & 0.24 & 0.24 & 0.24 \\
\hline 32 & 0.44 & 0.44 & 0.44 & 0.44 & 0.44 \\
\hline
\end{tabular}

\section{CONCLUSION}

This paper presents simulated annealing optimization for finding failure location in an array. It is capable of finding the failed element's location and percentage failure of a far-field defected radiation pattern successfully. Complete, partial, and $75 \%$ failure of the element in an array at different failure locations was traced out accurately by the proposed method. Far-field fault finding by SA reduces the need for near field measurements to find the failed location. When the failed location is known, it also helps to do a correction to the weights of other active elements to produce a similar radiation pattern as the original Chebyshev pattern. This method can be extended to planar arrays easily for future works.

\section{ACKNOWLEDGEMENTS}

This work was supported by University Tenaga Nasional Internal Grant (UNIIG 2018), Code: J5100508011.

\section{REFERENCES}

[1] M. D. Migliore and G. Panariello, "A comparison of interferometric methods applied to array diagnosis from nearfield data," IEE Proc. - Microwaves, Antennas Propag., vol. 148, no. 4, pp. 261-267, 2001.

[2] J. C. Bregains, F. Ares, and E. Moreno, "Matrix pseudo-inversion technique for diagnostics of planar arrays," Electron. Lett., vol. 41, no. 1, pp. 19-20, 2005.

[3] L. J. J., E. M. Ferren, D. P. Woollen, and K. M. Lee, "Near-Field probe used as a diagnostic tool to locate defective elements in an array antenna," IEEE Trans. Antennas Propag., vol. 36, no. 6, pp. 884-889, 1988.

[4] J. A. Lord, G. G. Cook, and A. P. Anderson, "Reconstruction of the excitation of array antennas from the measured near-field intensity using phase retrieval," Conf. Proc. - Eur. Microw. Conf., vol. 1, no. 22, pp. 525-530, 1992.

[5] O. M. Bucci, A. Capozzoli, and G. D. Elia, "Diagnosis of Array faults from far-field amplitude-only data," IEEE Trans. Antennas Propag., vol. 48, no. 5, pp. 647-652, 2000.

[6] C. Balamati and M. J. Rakesh, "Fault Detection in Antenna Arrays," in Soft Computing in Electromagnetics: Methods and Application, Cambridge University Press, pp. 124-154, 2016.

[7] B. K. Yeo and Y. Lu, "Array failure correction with a genetic algorithm," IEEE Trans. Antennas Propag., vol. 47, no. 5, pp. 823-828, 1999.

[8] S. U. Khan, M. K. A. Rahim, M. Aminu-baba, and N. A. Murad, "Correction of failure in linear antenna arrays with greedy sparseness constrained optimization technique,” PLoS One, vol. 12, no. 12, pp. 1-18, 2017.

[9] H. Patidar and G. K. Mahanti, "Failure correction of linear antenna array by changing length and spacing of failed elements," Prog. Electromagn. Res. M, vol. 61, no. October, pp. 75-84, 2017.

[10] W. P. M. N. Keizer, "Element failure correction for a large monopulse phased array antenna with active amplitude weighting," IEEE Trans. Antennas Propag., vol. 55, no. 8, pp. 2211-2218, 2007.

[11] A. Patnaik and C. Christodoulou, "Finding failed element positions in linear antenna arrays using neural networks," IEEE Antennas Propag. Soc. AP-S Int. Symp., no. 1, pp. 1675-1678, 2006.

[12] A. Patnaik, B. Choudhury, P. Pradhan, R. K. Mishra, and C. Christodoulou, "An ANN application for fault finding in antenna arrays,” IEEE Trans. Antennas Propag., vol. 55, no. 3 I, pp. 775-777, 2007. 
[13] N. Xu, C. G. Christodoulou, S. E. Barbin, and M. Martínez-Ramón, "Detecting failure of antenna array elements using machine learning optimization," IEEE Antennas Propag. Soc. AP-S Int. Symp., vol. 87131, no. 1, pp. 5753-5756, 2007.

[14] S. U. Khan, I. M. Qureshi, F. Zaman, A. Basit, and W. Khan, "Application of firefly algorithm to fault finding in linear arrays antenna," World Appl. Sci. J., vol. 26, no. 2, pp. 232-238, 2013.

[15] O. P. Acharya, A. Patnaik, and B. Choudhury, "Fault finding in antenna arrays using bacteria foraging optimization technique," 2011 Natl. Conf. Commun. NCC 2011, 2011.

[16] K. Yadav and H. Singh, "Application of iterative fast Fourier transform for fault finding in linear array antenna with various fault percentage," Proc. Int. Conf. Innov. Appl. Comput. Intell. Power, Energy Control. with Their Impact Humanit. CIPECH 2014, no. November, pp. 117-120, 2014.

[17] S. U. Khan, I. M. Qureshi, A. Naveed, B. Shoaib, and A. Basit, "Detection of defective sensors in phased array using compressed sensing and hybrid genetic algorithm," J. Sensors, 2016.

[18] S. U. Khan, I. M. Qureshi, F. Zaman, and W. Khan, "Detecting faulty sensors in an array using symmetrical structure and cultural algorithm hybridized with differential evolution," Front. Inf. Technol. Electron. Eng., vol. 18, no. 2, pp. 235-245, 2017.

[19] N. Metropolis, A. W. Rosenbluth, M. N. Rosenbluth, A. H. Teller, and E. Teller, "Equation of state calculations by fast computing machines," J. Chem. Phys., vol. 21, no. 6, pp. 1087-1092, 1953.

[20] S. Khezri and A. Mahdi Nazaari, "Solving wireless sensor network coverage problem using LAEDA," Indonesian Journal of Electrical Engineering and Computer Science (IJEECS), vol. 18, no. 1, pp. 452-458, 2019.

[21] H. Suyono, R. N. Hasanah, P. Mudjirahardjo, M Fauzan E. Purnomo, S. Uliyani, I. Musirin, L. J. Awalin, "Enhancement of the power system distribution reliability using ant colony optimization and simulated annealing methods," Indonesian Journal of Electrical Engineering and Computer Science (IJEECS), vol. 17, no. 2, pp. 877-885, 2019.

[22] N. Boopalan, A. K. Ramasamy, and F. H. Nagi, "Power electronics component location and heat sink length optimization - hybrid electrical vehicle (HEV)," Indian J. Sci. Technol., vol. 9, no. 28, pp. 1-6, 2016.

[23] S. S. Sadiq, A. M. Abdulazeez, and H. Haron, "Solving multi-objective master production schedule problem using memetic algorithm," Indonesian Journal of Electrical Engineering and Computer Science (IJEECS), vol. 18, no. 2, pp. 938-945, 2020.

[24] J. A. Rodriguez and F. Ares, "Optimization of the performance of arrays with failed elements using the simulated annealing technique," J. Electromagn. Waves Appl., vol. 12, no. 12, pp. 1625-1638, 1998.

[25] C. Wykes, P. Webb, F. Nagi, and I. Gibson, "Ultrasonic arrays for Robot control," in Symposium on Sensory Systems for Robot Control, 1992.

[26] F. Nagi and W. Hung, “Array beampattern using goal,” Pertanika J. Sci. Technol., vol. 15, no. 1, pp. 25-34, 2007.

\section{BIOGRAPHIES OF AUTHORS}

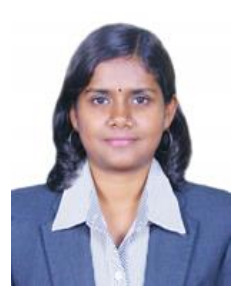

Navaamsini Boopalan was born in Penang, Malaysia on Nov 1989. She completed her Bachelor Degree in Electrical and Electronic Engineering with University Tenaga Nasional (UNITEN) in year 2012. She joined Silterra Malaysia as Engineer in the same year. From year 2014 to now she is attached to Department of Communication Engineering, UNITEN as Research Officer. Meanwhile, she pursued and obtained her M.Eng in Electrical Engineering from UNITEN in 2017. Her research interests center around optimization and signal and systems.

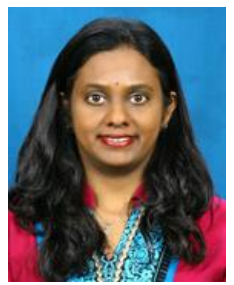

Agileswari K. Ramasamy was born in Taiping, Perak and received her B.Sc (Engineering) degree from Purdue University, USA in 1995 under the sponsorship of Yayasan Tenaga Nasional. She obtained her MSc. (Control System) from Imperial College, London in 2001 and PhD in Electrical Engineering from Universiti Tenaga Nasional (UNITEN), under the sponsorship of UNITEN. She is currently an Associate Professor in the Department of Electronics Communication Engineering at UNITEN and serving as a Deputy Dean of Research and Postgraduate for College of Engineering, UNITEN. She is also a Chartered Member of the Institution of Engineering and Technology (IET). She is currently active in research and consultancy in control system, power system, power quality, energy efficiency and renewable energy. She has headed several research projects to date and has successfully published several indexed journals.

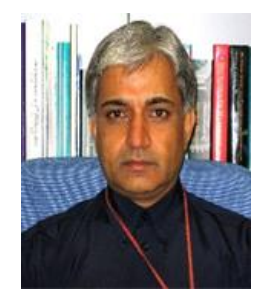

Farrukh Hafiz Nagi received the BE(MECH), from NED University of Engineering \& Technology in year 1981 and the Master in Industrial Engineering from University of Miami in year 1989. He obtained his Doctorate from University of Nottingham, UK in year 1993. He is working as a lecturer from year 1995. Currently he is a Professor in the Department of Mechanical Engineering at UNITEN. He is actively involved in MATLAB activities in the country and had conducted numerous hands-on MATLAB/SIMULINK, Optimization workshops. His research Area includes, Real time fuzzy Bang-Bang control with TI DSP. He has designed and developed Automated Racking System for Vacuum Circuit Breakers (VCB) and Automated switching system for power distribution system. For further details on his work please visit http://metalab.uniten.edu.my/ farrukh/. 